\title{
The Impact of Indirect Feedback on Learning Writing
}

Linh Phan

Nguyen Quang Dieu Gifted High School, Dong Thap Province

\begin{abstract}
Correction of writing errors in the classroom requires much time and work from the instructor. A learner-centered approach helps students notice and correct their own errors. This presentation offers instructors techniques to give students indirect feedback, and reviews the major influences on the acquisition of writing
\end{abstract} skills.

\section{Session Description}

Although techniques in writing correction are often analyzed in academic articles about learning and teaching, there is surprisingly little recent research on systematic investigations of the power of indirect feedback in the classroom (Kluger and DeNisi, 1996). In this presentation, the presenter reports on a conceptual analysis of indirect feedback and experiments related to the usefulness of indirect feedback to accelerate the teaching and learning process in the classroom. The presenter then identifies the most effective kinds of indirect feedback from the research. Specifically, the research evidence mainly supports two types of indirect feedback: self- and peer-correction to help increase the learners' writing ability in the EFL classroom. The presenter's primary concern is to focus on kinds of feedback: (1) self-correction with non-coded feedback, and (2) peercorrection as a conference in the classroom (Chandler, 2004). This presentation will be useful to EFL teachers, especially writing teachers who would like to work with EFL learners in high schools, specifically 10th grade or low intermediate level students. Finally, the presenter will suggest ways to increase the effectiveness of selfand peer-correction. Moreover, the teachers’ workload could be partly reduced with the application of these techniques, which not only help learners reduce the errors in their writing but also enhances the students’ ability to correct their own errors. 


\section{References}

Chandler, J. (2004). A response to Truscott. Journal of Second Language Writing, 13, 345-348.

Kluger, A. N., \& DeNisi, A. (1996). The effects of feedback interventions on performance: A historical review, a meta-analysis, and a preliminary feedback intervention theory. Psychological Bulletin, 119 (2), 254284.

Back to Table of Contents 